\title{
An experimental and numerical study of forces and residual stresses in AISI 316L stainless steel joints due to conventional and pulse gas tungsten arc welding
}

\author{
Ivan Muhtarov ${ }^{1 *}$, Teofil Iamboliev ${ }^{2}$, Veselin Tsonev ${ }^{3}$ \\ ${ }^{1}$ Visteon Electronics Bulgaria, 90 Tsarigradsko Shosse Blvd., Capital Fort Building, 1000 Sofia, Bulgaria \\ ${ }^{2}$ Technical University - Sofia, Plovdiv Branch, "Mechanical Technologies” Department, 25 Tsanko Diustabanov St., 4000 Plovdiv, \\ Bulgaria \\ ${ }^{3}$ Technical University - Sofia, "Strength of Materials" Department, 8 Kliment Ohridski Blvd., 1000 Sofia, Bulgaria
}

\begin{abstract}
This paper aims to present the results of a numerical and experimental study of the temperature field, internal forces and the residual stresses in $2 \mathrm{~mm}$ thick autogenous welds of AISI 316L stainless steel produced by continuous and pulse current gas tungsten arc welding. A special experimental device was used to measure the temperature and the internal forces due to the welding. The welds were qualified for internal and external weld imperfections according to ISO 15614-1. FEM software ANSYS ${ }^{\circledR}$ Multyphysics $^{\text {TM }}$ was applied in order to solve the thermal and mechanical problems. Normal residual stresses were measured by the hole-drilling strain gauge method in the continuous current weld. The peak value of the longitudinal stress was $80 \%$ of the base metal yield stress. The magnitude of the numerically obtained residual stress values was found to be $16 \%$ to $19 \%$ above the measured one in the longitudinal and transverse direction, respectively. The experimental device used in this study allowed for a real time measurement of forces far from the weld seam. On the basis of the correspondence between the calculated and measured forces the numerical results were verified. Therefore, this device might open up new possibilities for determining thermo-mechanical material data.
\end{abstract}

\section{Introduction}

Stainless steel is a desired material for a variety of structural engineering applications. Austenitic stainless steels, for example 316L, combine excellent mechanical properties, corrosion and heat resistance ranging from cryogenic up to high temperatures. They are used as equipment in chemical plants, power plants, food industry, etc. [1].

Continuous current gas tungsten arc welding (CCGTAW) is a key technology used for joining thin plates or thin-wall pipes in equipment manufacturing. It is known for its flexibility, providing a stable concentrated arc and narrow heat-affected zone with minimal distortion of the weld joint. If the thickness of the components to be joined is of up to $3 \mathrm{~mm}$, a filler metal is not required and the process can be applied autogenously, hence, providing an equal chemical composition of the weld metal and the base metal $[2,3]$.

The pulse current gas tungsten arc welding (PCGTAW) is a variant of the constant current welding process. It is the changing of welding current from peak amperage to a background amperage rapidly and repeatedly. This process is useful whenever welding heat input must be minimized or penetration accurately and repetitively controlled [2, 4-6]. This is particularly advantageous for welding thin sheet or when welding the root pass of a multilayer weld in thicker sections. The superior mechanical properties (higher yield strength and hardness), preferred microstructures in the weld metal region (very fine equiaxed grains with higher amount of precipitates) and favorable residual stress field in the weld metal region (large magnitude of compressive stress) as well as less warpage are the reasons for better performance of the PC-GTAW joints and the advantages of using PC-GTAW over the conventional GTAW process for welding of stainless steels [4-6]. It has been estimated that the average current needed for PC-GTAW is by 10 to $15 \%$ less than the average current used for GTAW [5].

During welding, a non-uniform heat introduction in the components results in a non-uniform temperature field. After the completion of welding and cooling to room temperature, residual stresses are built up, causing distortion of the weld joint. This may sometimes lead to a premature failure. There are several factors affecting the extent of the distortion and residual stresses. The most important of them are the welding parameters, the thickness of the components to be joined, the degree of restraint, and the welding sequence, etc. [2, 3, 6-9].

Experimentally residual stresses may be measured by means of the hole drilling method $[10,11]$, ultrasonic methods [12] as well as X-ray and neutron diffraction methods $[13,14]$. Numerical simulation by means of a

* Corresponding author: i_muhtarov@tu-sofia.bg 
finite element code is an efficient tool for determining the residual distribution stress within the weld [15-17]. Its practical application may be limited by missing or not precisely determined material data dependent on temperature $[16,18]$.

There is a great number of studies measuring and modelling residual stress and distortion as a result of pulse gas metal arc welding [19-27]. However, the number of works dealing with experimental and numerical determination of the residual stress and distortion in PCGTA welds is low. In an experimental work on the effect of PC-GTAW on the residual stress of 304 and 310 stainless steel welds the hole drilling strain-gauge method has been applied. It was found out that the magnitude of the residual stress can be reduced when welding with high pulse frequency, large pulse spacing, high base current/pulse current amplitude and base time/pulse time duration ratios. Higher residual stresses were determined in the 310 welds than in the 304 welds due to the difference in the thermophysical properties of these alloys [6].

Most of previous work has been focused on the technological welding aspects using austenitic $[5,6,9,21$, $22]$ and ferritic [17, 19, 24, 25] stainless steels as well as aluminum alloys [20]. Less attention has been paid to numerical studies of the residual stresses and distortions of these steel alloys subjected to GTAW.

In view of the above, this paper presents a numerical and experimental study of the temperature field, internal forces and the residual stresses in thin plates of $316 \mathrm{~L}$ subjected to autogenous CC-GTAW and PC-GTAW.

\section{Experimental procedure}

\subsection{Material}

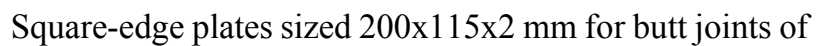
stainless steel alloy AISI 316L were cut. The chemical composition of this alloy is listed in Table 1. After degreasing, the plates were tack-welded so that the welding gap was approximately zero.

Table 1. Chemical composition of steel alloy 316L.

\begin{tabular}{|c|c|}
\hline Element & $\mathbf{\%}$ \\
\hline $\mathrm{C}$ & 0,017 \\
\hline $\mathrm{Si}$ & 0,54 \\
\hline $\mathrm{Mn}$ & 1,76 \\
\hline $\mathrm{S}$ & 0,002 \\
\hline $\mathrm{P}$ & 0,034 \\
\hline $\mathrm{Cr}$ & 16,9 \\
\hline $\mathrm{Ni}$ & 10,1 \\
\hline $\mathrm{Mo}$ & 2,06 \\
\hline $\mathrm{N}$ & 0,045 \\
\hline
\end{tabular}

\subsection{Experimental device}

An experimental device was developed to include the welded samples in a statically indeterminate structure, allowing measurement of internal forces and temperature in selected points. The setup is shown in Fig. 1. A wide flange standard beam 1 was used as a holding structure. The plates 4 to be joined were mounted on it by means of clamps 2 and 3 . The cylindrical part 5 of the clamp 3 was a hollow section of $1,5 \mathrm{~mm}$ wall thickness. After machining the clamp was hardened and tempered up to 45 HRC. Resistance strain gauges of type LK11O 3/350 with gauge factor $\mathrm{k}=2,00$ made by $\mathrm{HBM} \mathrm{GmbH}$ were glued onto the surface of the hollow section and covered with a mechanically protecting layer. The maximum permissible temperature of the glue and the strain gauges was $160{ }^{\circ} \mathrm{C}$. In order to prevent sensor overheating when welding under high heat input per unit length, there was a water cooling system of the clamp represented by the inlet and outlet pipes 13. All measuring circuits were executed as full Wheatstone bridges. Cable 6 connected the strain gauges to an amplifier and further, to a PC. Hence, clamp 3 and cylindrical part 5 acted as a combined dynamometer.

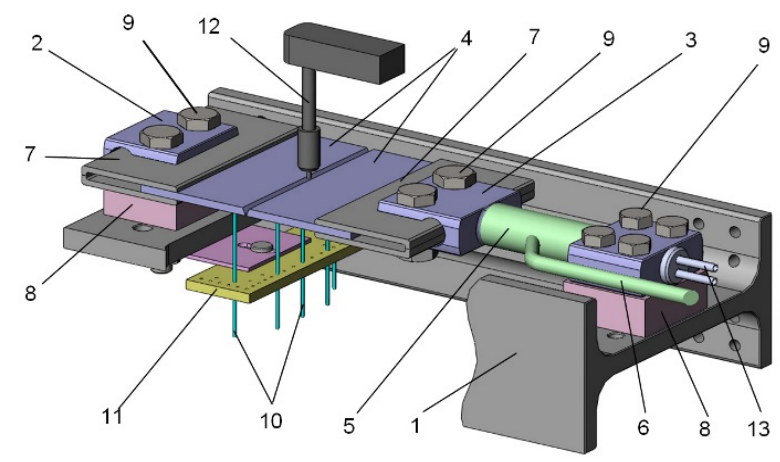

Fig. 1. Experimental device: 1 - steel profile; 2, 3-clamps; 4 - plates to be joined; 5 - cylindrical part; 6 - cable;

7 - fitting plates; 8 - distance plates; 9 - bolt;

10 - thermocouples; 11 - supporting plate; 12 - welding torch; 13 - inlet and outlet cooling pipes.

Distance plates 8 helped to adjust the vertical position of the sample. They were clamped using fitting plates 7 of suitable thickness. The clamp constraint was provided by pressure achieved after screwing bolts 9 .

The principal axis orientation of the dynamometer and the positions of the strain gauges are visible in Fig. 2 . The internal forces due to welding were measured by the dynamometric clamp 3 as follows: the torque moment $M_{x}$ around axis $x$, the bending moments, $M_{y}$ and $M_{z}$ around axes $y$ and $z$, respectively, as well as the normal force $N_{x}$ along axis $x$.

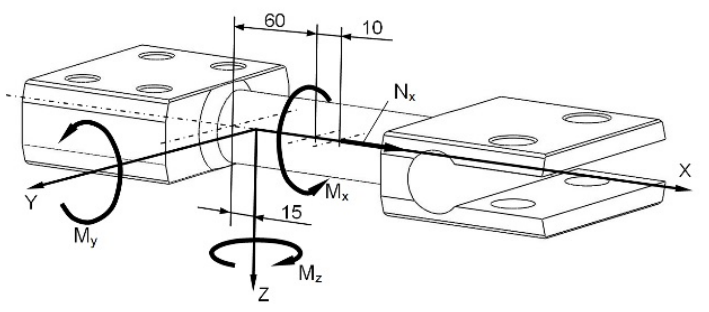

Fig. 2. Internal forces measured and positions of the strain gauges.

Prior to welding, the dynamometer was calibrated in order to convert the measured strain into relevant forces. The calibration was accomplished using appropriate 
appliances in accordance with ISO 376. The total error of the dynamometer was within $0,5 \%$. The interference between the measuring channels was less than the common limit of $5 \%$ in engineering practice.

The insulated NiCr-Ni thermocouples 10 of diameter $3 \mathrm{~mm}$ and precision class 2 providing $\pm 0,75 \%$ error within the temperature range $333-1100{ }^{\circ} \mathrm{C}$ were used to measure the temperature in selected points at the weld seam. They were supported by a plate 11 (Fig.1), and fixed in the blind drilled holes of the tacked plates prior to welding. The temperature was measured along the welding direction in 4 points (T1, T2, T3, T4) and away from the edge in 2 points (T5, T6) according to Fig. 3.

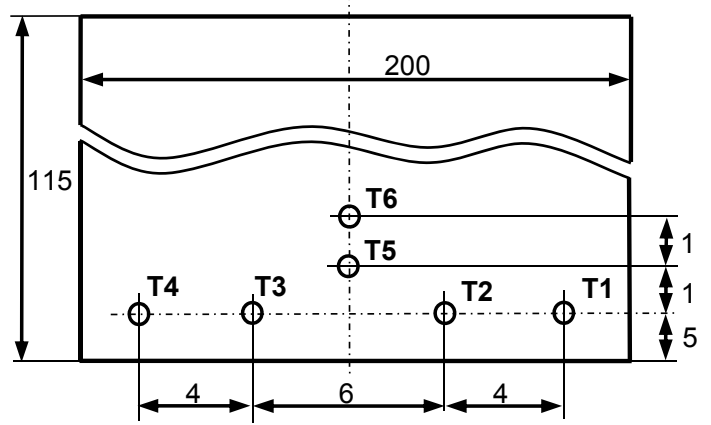

Fig. 3. Location of points for temperature measurement.

\subsection{Experimental layout}

The experimental layout is shown in Fig. 4. The strain gauge signals from dynamometer 1 were processed by a digital multichannel strain gauge amplifier 2. Further, PC 3 with appropriate software was used to record the signals and control the amplifier 2. Thermocouples 4 were connected to processing unit 5 via shielded cables. An interface adapter transformed the signals in an appropriate format for the PC. The PC was used to save and visualize the thermal cycles.

\subsection{Welding conditions}

Both the CC-GTAW and the PC-GTAW were applied autogenously without backing. The following welding conditions were applied:

- CC-GTAW: current 100 A, arc voltage 9,7 V, welding velocity $3,5 \mathrm{~mm} / \mathrm{s}$, heat input $1524,3 \mathrm{~J} / \mathrm{cm}$;

- PC-GTAW: pulse current $158 \mathrm{~A}$, base current $45 \mathrm{~A}$, pulse on time 0,47 , frequency $3 \mathrm{~Hz}$, average current 98,1 A, arc voltage $8,7 \mathrm{~V}$, welding velocity $3,5 \mathrm{~mm} / \mathrm{s}$, heat input $1341,3 \mathrm{~J} / \mathrm{cm}$.

A thoriated W-electrode with a diameter of $2,4 \mathrm{~mm}$ was used, as well as Ar shielding with a flow rate of 6,5 $1 / \mathrm{min}$ and $5 \mathrm{l} / \mathrm{min}$ for the face side and the root side of the weld seam, respectively. The welding machine was Kempi Mastertig 2300 allowing for a precise set up of the parameter values. The torch was moved by a carriage ensuring constant welding velocity.

The welds were qualified for internal and external weld imperfections according to ISO 15614-1 [28]. After non-destructive testing the macrostructure was studied in a weld cross section.

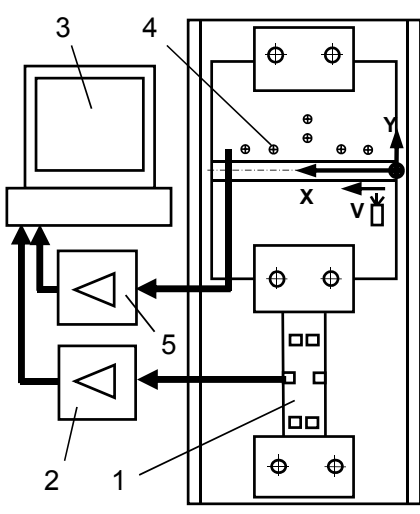

a)

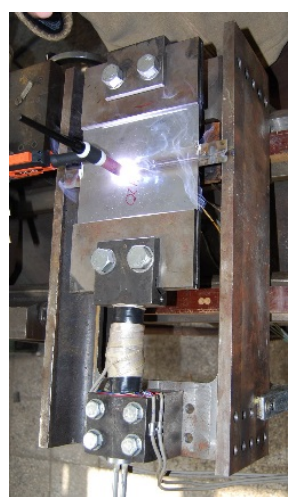

b)
Fig. 4. Experimental layout: a) set up: 1 - dynamometer; 2 -amplifier; 3 - PC; 4 -thermocouples; 5 - processing unit; b) view during welding.

\subsection{Residual stress measurement}

The residual stress measurement was accomplished by means of the hole-drilling method following a standard ASTM procedure $[10,11]$. It was carried out after weld cooling to room temperature and dismantling from the experimental device. Two sets of strain gauges RY61-120 were used - one of them was active and the other one was put on a neighboring plate to compensate for the temperature effect. The location of the strain gauges at measuring point SG on the CC-GTA weld sample is illustrated in Fig. 5. The hole-drilling was carried out with a special guiding device equipped with a drill of $1,3 \mathrm{~mm}$ diameter at $1000 \mathrm{rpm}$. The stress measurement was accomplished using appropriate HMB equipment.

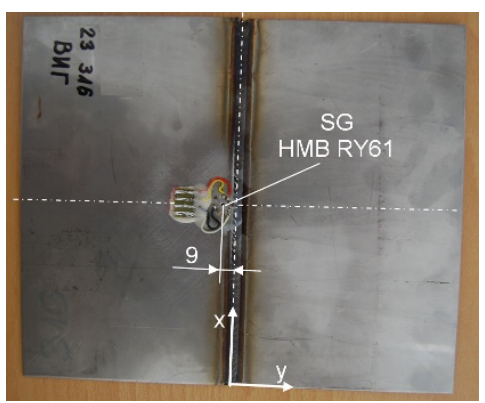

Fig. 5. Location of point SG and strain gauge rosette on a CCGTA weld sample.

\section{Computational models}

FEM software ANSYS $^{\circledR}$ Multiphysics $^{\mathrm{TM}}$ was used to develop the computational models. They were produced as sequential decoupled analyses. This approach has already been used to study thermal fields, forces and stresses in single and multi-pass welds of variousthickness plates [24-26]. The thermo-mechanical problem was divided into two parts solved sequentially [15]. The thermal field was calculated. Thereafter, the mechanical solution was conducted determining the stresses and strains. 
The geometrical model shown in Fig. 6 was the same for both the CC-GTAW and PC-GTAW processes. The body of the experimental device was neglected, since it was assumed to be rigid. The clamp and the dynamometer were fixed on the surfaces connected with the experimental device body. The finite elent mesh in heataffected zone (HAZ) can be seen in Fig. 7. Prismatic solid elements of small average size were used to build a fine mapped mesh in this zone. Volumes far from the weld seam were meshed with elements of bigger size. Hence, the total number of the model elements was decreased.

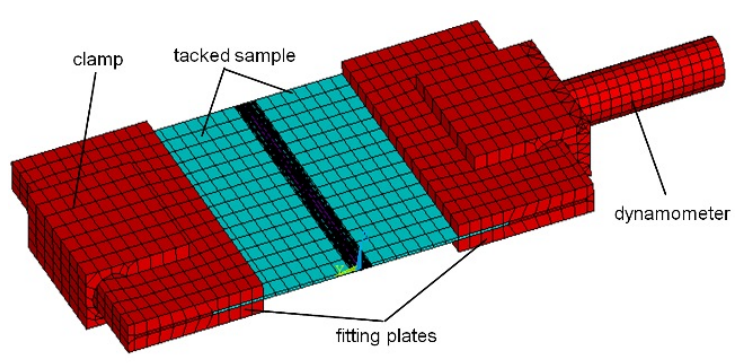

Fig. 6. Computer model of the investigated weld joints.

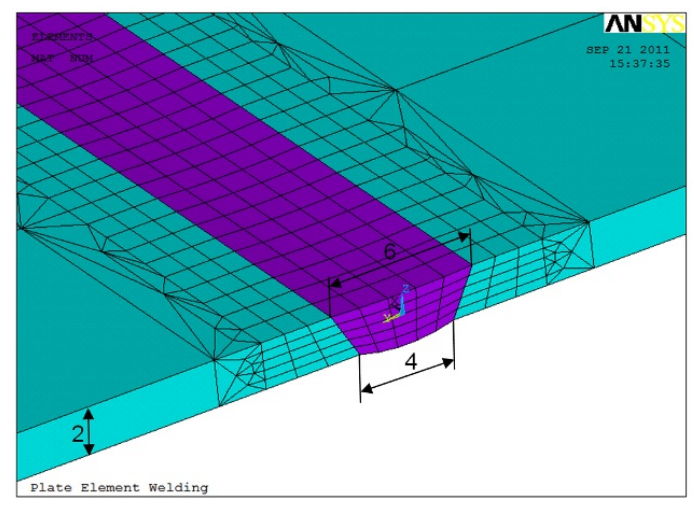

Fig. 7. Mesh in the weld heat-affected zone.

A double ellipsoidal heat source with Gaussian distribution of the thermal flux $[8,15]$ was applied in the model of the conventional CC-GTAW process. For the heat input in the PC-GTAW model two types of heat sources were used - a constant double ellipsoidal and a pulsing spherical source. The constant double ellipsoidal source was used to supply the heat due to the base current. The pulsing spherical source provided the heat resulting from the increased pulse current. The parameters of the sources were tuned with test solutions, until the fusion zone was properly represented in the models. The movement of the sources was realized by defining them in a local Cartesian coordinate system moving in regard to a global stationary coordinate system [15].

In the presented numerical models the weld seam formation was accomplished by an activation and deactivation technique $[28,29]$. This technique was also used in order to determine the residual stresses in the welded samples after disassembling from the experimental device. This was accomplished by deactivating the fitting plates at $t=1800 \mathrm{~s}$ after the start of the welding process. Thereby, the samples in the model were released from the constraints. Force determination in the cylindrical section of the dynamometric clamp was done through classical integral relation between stresses and internal forces.

The data for the material thermodynamical and thermomechanical properties used for the numerical solution were adopted from [30] as shown in Table 2, where: $T$ - temperature; $c$ - thermal capacity; $k$ - thermal conductivity; $E$ - Young's modulus; $v$ - Poisson's ratio; $\sigma_{y}-$ yielding stress; $E_{T}-$ tangent modulus; $\alpha$ - thermal expansion.

Table 2. Material properties data [30].

\begin{tabular}{|c|c|c|c|c|c|c|c|}
\hline $\begin{array}{c}\boldsymbol{T} \\
{ }^{\circ} \mathbf{C}\end{array}$ & $\begin{array}{c}\boldsymbol{c} \\
\mathbf{J} / \mathbf{k g . K}\end{array}$ & $\begin{array}{c}\boldsymbol{k} \\
\mathbf{W} / \mathbf{m} . \mathbf{K}\end{array}$ & $\begin{array}{c}\boldsymbol{E} \\
\mathbf{G P a}\end{array}$ & $\begin{array}{c}\boldsymbol{v} \\
-\end{array}$ & $\begin{array}{c}\boldsymbol{\sigma}_{\boldsymbol{y}} \\
\mathbf{M P a}\end{array}$ & $\begin{array}{c}\boldsymbol{E} T / \boldsymbol{E} \\
-\end{array}$ & $\begin{array}{c}\boldsymbol{\alpha} \\
{ }^{\circ} \mathbf{C}^{-1}\end{array}$ \\
\hline 20 & 442 & 15,0 & 200 & 0,278 & 318 & 0,014 & $11,8.10^{-6}$ \\
\hline 200 & 515 & 17,5 & 185 & 0,288 & 205 & 0,014 & $12,6.10^{-6}$ \\
\hline 400 & 563 & 20,0 & 170 & 0,298 & 132 & 0,014 & $13,6.10^{-6}$ \\
\hline 600 & 581 & 22,5 & 153 & 0,313 & 105 & 0,014 & $14,8.10^{-6}$ \\
\hline 800 & 609 & 25,5 & 135 & 0,327 & 77 & 0,014 & $14,7.10^{-6}$ \\
\hline 1000 & 631 & 28,3 & 96 & 0,342 & 50 & $1.10^{-4}$ & $14,0.10^{-6}$ \\
\hline 1200 & 654 & 31,1 & 50 & 0,350 & 10 & $1.10^{-4}$ & $13,8.10^{-6}$ \\
\hline 1340 & 669 & 33,1 & 10 & 0,351 & 10 & $1.10^{-4}$ & $13,6.10^{-6}$ \\
\hline 1400 & 675 & 66,2 & 10 & 0,353 & 10 & $1.10^{-4}$ & $12,7.10^{-6}$ \\
\hline
\end{tabular}

\section{Results and discussion}

\subsection{Weld quality}

Fig. 8 presents a view of the macrostructure of full penetration welds. The weld geometry represented a smooth weld bead profile excluding stress concentration. No weld imperfections were found in the welds, hence, the weld covered the highest quality requirements of ISO 5817, level B [28]. The weld bead area of the PC-GTAW and CC-GTAW were found to be $8,14 \mathrm{~mm}^{2}$ and 11,96 $\mathrm{mm}^{2}$, respectively. The difference in the area could be attributed to the $12 \%$ lower heat input of the PC-GTAW as compared with that of the CC-GTAW.

a)

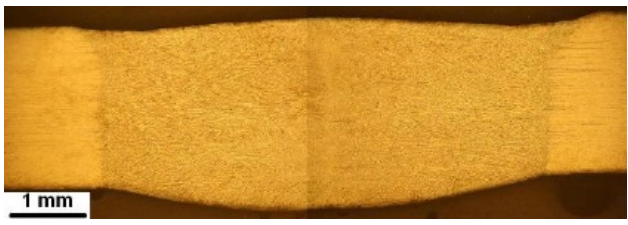

b)

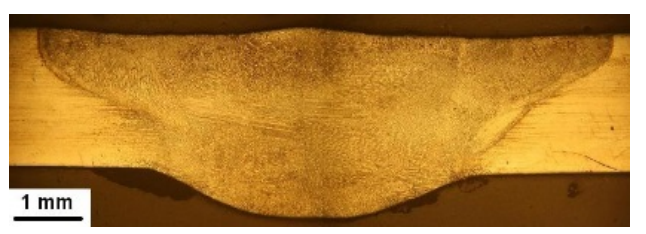

Fig. 8. Macrostructure of welds with figures for the heat input and the weld bead area: a) PC-GTAW, $q=1341,3 \mathrm{~J} / \mathrm{cm}$, $A=8,14 \mathrm{~mm}^{2}$; b) CC-GTAW, $q=1524,3 \mathrm{~J} / \mathrm{cm}, A=11,96 \mathrm{~mm}^{2}$.

\subsection{Weld thermal cycles}

The weld thermal cycles taken at points T2 and T6, Fig. 3, are illustrated in Fig. 9. The duration of the welding process was about $57 \mathrm{~s}$. The peak temperatures at T2 to 

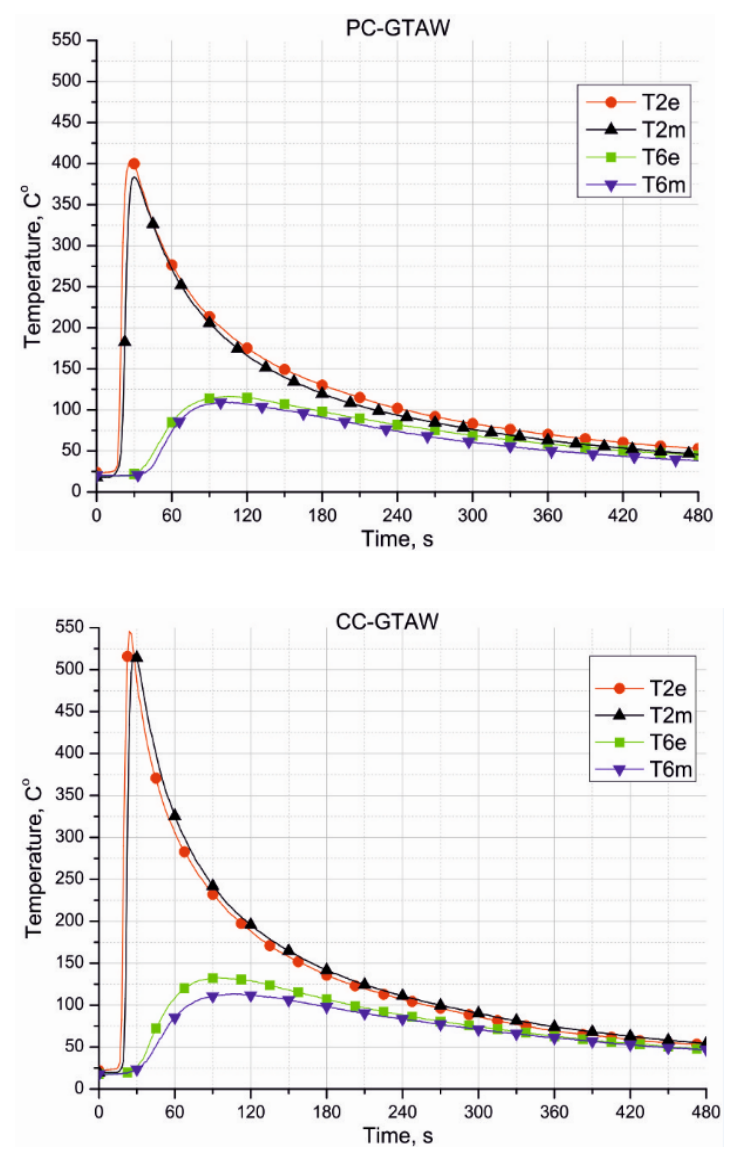

Fig. 9. Numerically (subscript $m$ ) and experimentally (subscript $e$ ) obtained thermal cycles at points T2 and T6

$\mathrm{T} 4$ were found to be much higher than those at point T6 because of the smaller distance to the heat source during welding. After about $480 \mathrm{~s}$, on cooling, the curves are brought close together corresponding to the stage of heat equalization due to heat conduction. Also numerically obtained thermal cycles are superimposed showing good correlation to the experimental curves.

The peak temperatures occurring with the PC-GTAW were lower than those with the CC-GTAW. For example, peak temperatures of $400^{\circ} \mathrm{C}$ and $520^{\circ} \mathrm{C}$ were measured at point T2 for the PC-GTAW and the CC-GTAW, respectively. The peak values at point $\mathrm{T} 6$ were $120^{\circ} \mathrm{C}$ and $133^{\circ} \mathrm{C}$ for each process. The lower peak temperature of the PC-GTA welds resulted in a narrower HAZ and better mechanical properties as found earlier [31].

\subsection{Internal forces}

The kinetics of the internal forces, Fig. 2, arising in the sample during welding and after its completion are shown in Fig. 10 to Fig. 12. Bending moment $M_{y}$ originating from an angular distortion of the weld was measured to be positive as demonstrated in Fig. 10. On weld cooling, $M_{y}$ increased abruptly due to an increase of the modulus of elasticity. At different stages of cooling, $M_{y}$ of the PCGTA welds was lower than that of the CC-GTA welds. For example, just after welding completion at $t=57 \mathrm{~s}$ $M_{y}=9 \mathrm{Nm}$ for the PC-GTA welds and $M_{y}=10,5 \mathrm{Nm}$ for the CC-GTA welds. Later at $t=480 \mathrm{~s}$ the corresponding measured values were $M_{y}=11,25 \mathrm{Nm}$ and $M_{y}=13,40 \mathrm{Nm}$,
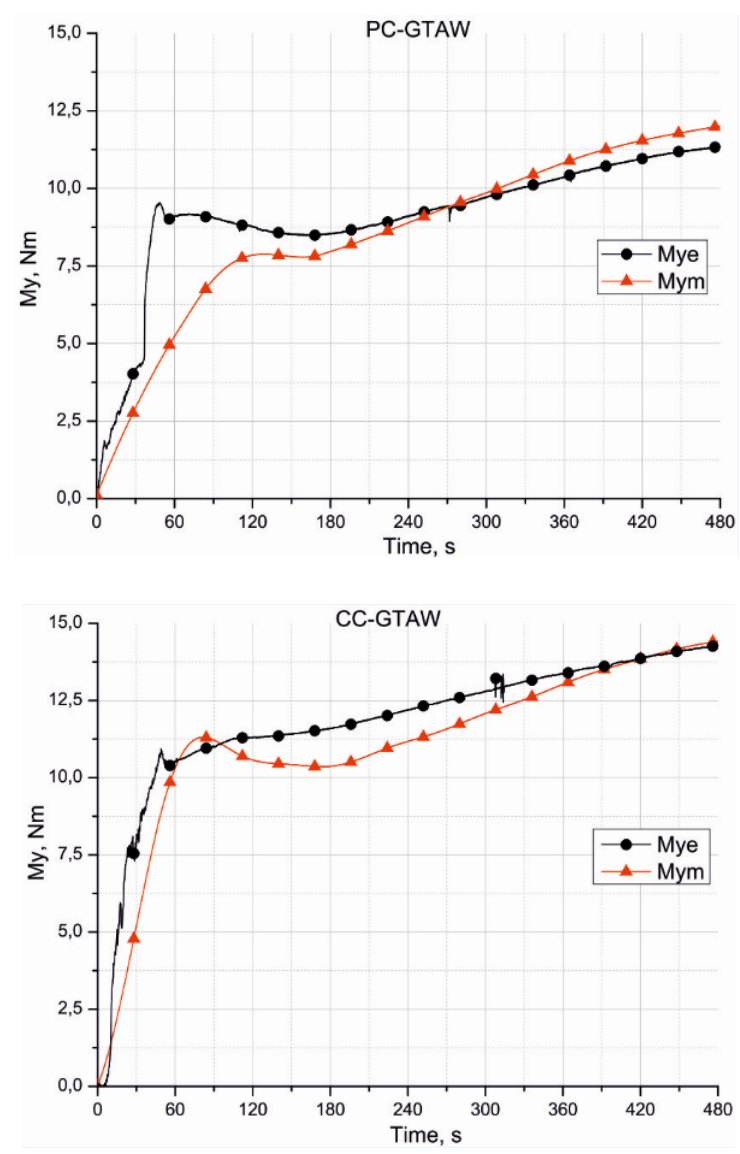

Fig. 10. Kinetics of the measured and calculated bending moment $M_{y}$.

respectively. The modeled $M_{y}$ curves are superimposed in Fig. 10. After welding completion there is a good correlation between the experiment and the model of both the PC-GTAW and CC-GTAW processes.

Similar observations were established considering the kinetics of the bending moment $M_{z}$ in Fig. 11. The initial negative value of $M_{z}$ could be attributed to the linear expansion of the plate edges after the welding start, which led to an angular distortion in the plane $z=0$. When half of the weld length was accomplished the stiffness of the sample arose and the rate of deformation slowed down reaching a negative peak value. Even before welding completion $M_{z}$ increased and became positive due to a powerful longitudinal shrinkage on cooling of the already deposited weld metal. After welding completion on further cooling the rate of the $M_{z}$ rise was lower as corresponding to the lessening cooling rate of the weld. The $M_{z}$ values measured in the PC-GTA welds were lower than those obtained in the CC-GTA welds. For example, at $t=480 \mathrm{~s} M_{z}$ approximated $5 \mathrm{Nm}$ in the PC-GTA welds and $7 \mathrm{Nm}$ in the CC-GTA welds, the former amounting to about $70 \%$ of the latter. A good correlation between the experimentally and numerically obtained $M_{z}$ values for both the PC-GTAW and CC-GTAW processes was found.

The torque moment was also time dependent and varied within the range $M_{x}=-0,5 \mathrm{Nm}$ to $M_{x}=1 \mathrm{Nm}$. These values were found to be small and insignificant, so an $M_{x}$ diagram is not provided. 

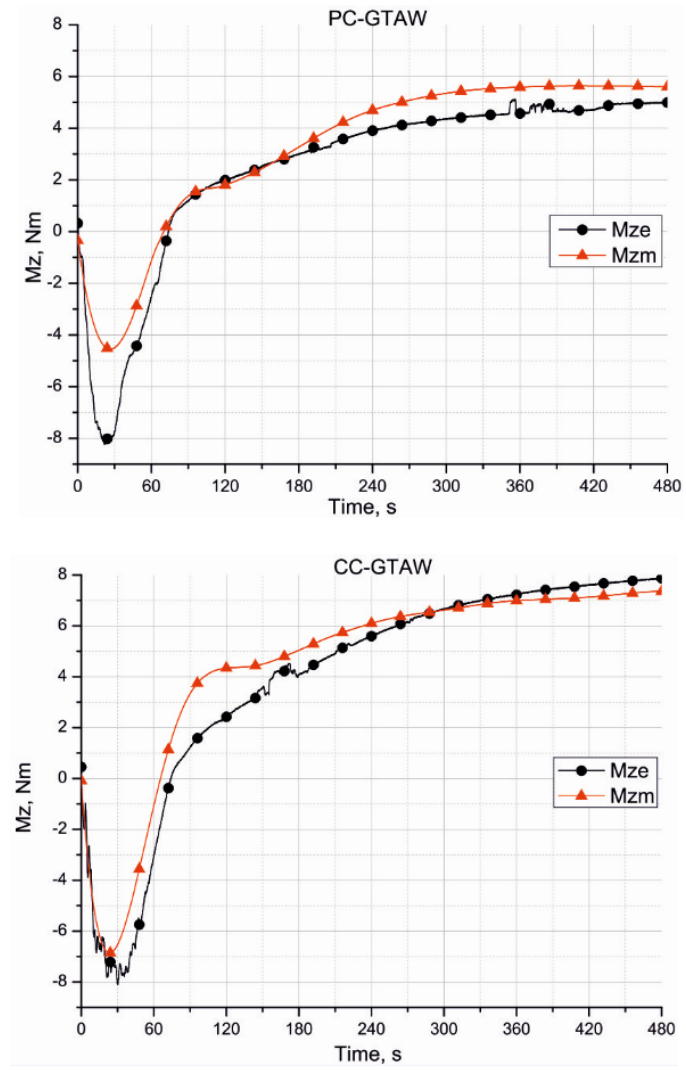

Fig. 11. Kinetics of the measured and calculated bending moment $M_{z}$.

Short-time negative values of normal force $N_{x}$ were established just after the beginning of the welding process, as demonstrated by the experimental curve in Fig. 12. These were to be related to a transverse expansion of the weld sample, causing pressure on the dynamometer. On cooling, the expansion turned to shrinkage of the deposited weld metal, so $N_{x}$ became positive and, after a steady increase, reached its final constant value. Also $N_{x}$ showed lower values for the PC-GTA welds compared with those of the CC-GTA welds as follows: at $t=180 \mathrm{~s}$ $N_{x}=1750 \mathrm{~N}$ for the PC-GTA welds and $N_{x}=2000 \mathrm{~N}$ for the CC-GTA welds; also, at $t=600 \mathrm{~s}$, the corresponding residual values were $2250 \mathrm{~N}$ and $2500 \mathrm{~N}$. A good correlation between the experiment and the model was reached about $600 \mathrm{~s}$ after the arc had extinguished.

\subsection{Residual stress}

As mentioned previously, the weld stresses were measured in the CC-GTA weld using the hole drilling method. The experimental results obtained are shown in Fig. 13. It can be seen that the longitudinal residual stress $\sigma_{x}$ is positive and comes up to $222 \mathrm{MPa}$, which represents about $70 \%$ of the base metal yield strength. In addition, the transverse positive residual stress $\sigma_{y}$ amounted to $75 \mathrm{MPa}$, hence, a ratio $\sigma_{x} / \sigma_{y}=2,96$ applied.

The normal stresses in the CC-GTAW sample were modelled from the beginning of the welding process. They were superimposed in Fig. 13. During welding there was a transient process of stress development. It was
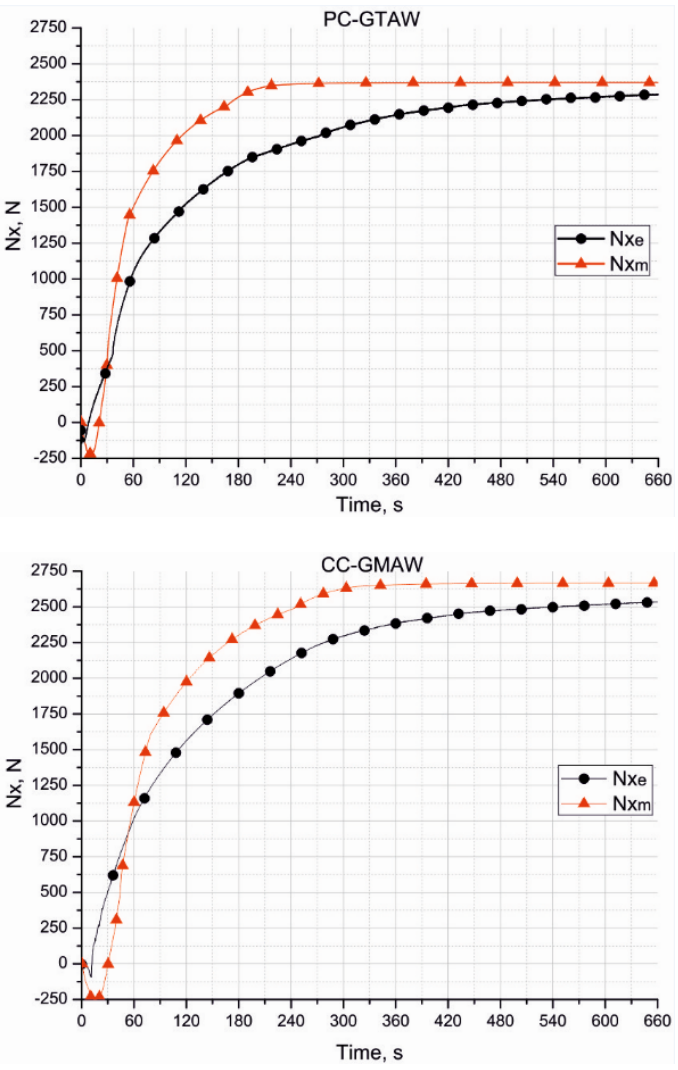

Fig. 12. Kinetics of the measured and calculated normal force $N_{x}$.

followed by a steady stress increase up to the residual stress values reached at $t=660 \mathrm{~s}$ after the welding start. The longitudinal stress $\sigma_{x}=271 \mathrm{MPa}$ was higher than the transverse stress $\sigma_{y}=104 \mathrm{MPa}$ and a relation applied $\sigma_{x} / \sigma_{y}=2,6$. These residual stress values applied for the weld sample constrained in the experimental device according to Fig 1 and Fig. 4. After weld dismantling at $t=1800 \mathrm{~s}$ the actual residual stresses decreased to $\sigma_{x}=258 \mathrm{MPa}$ and $\sigma_{y}=89 \mathrm{MPa}$ causing an abrupt change of the curves as pointed by the arrows in Fig. 13. In this case, the residual stress ratio was $\sigma / x \sigma_{y}=2,90$, thus, approximately confirming the one of 2,96 obtained from the measurement.

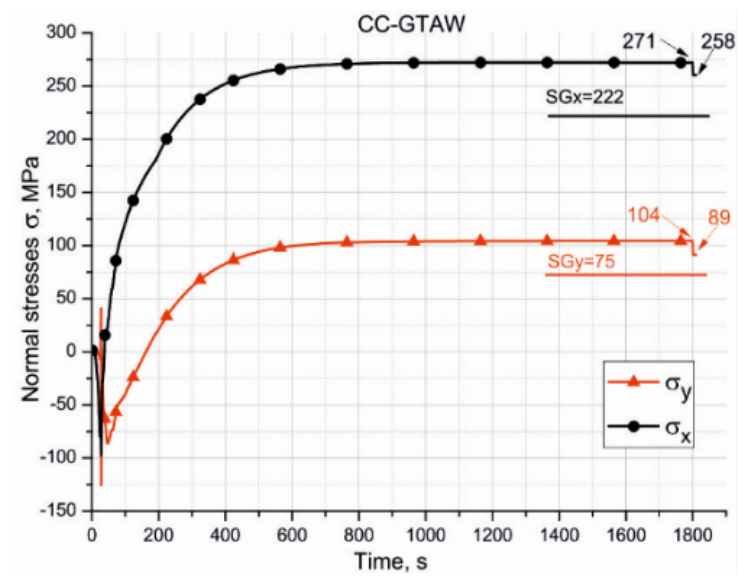

Fig. 13. Calculated and measured normal stresses in point SG of the CC-GTAW sample. 
The modelled distribution of the normal residual stresses in longitudinal and transverse direction at $t=1805 \mathrm{~s}$ of the CC-GTA weld is shown in Fig. 14. The numerically obtained residual stresses were found to be $16 \%$ to $19 \%$ higher than the measured values. First of all, these discrepancies could be attributed to the unreliable thermomechanical material data above $900^{\circ} \mathrm{C}$, which were used for the calculation presented in Table 2 .
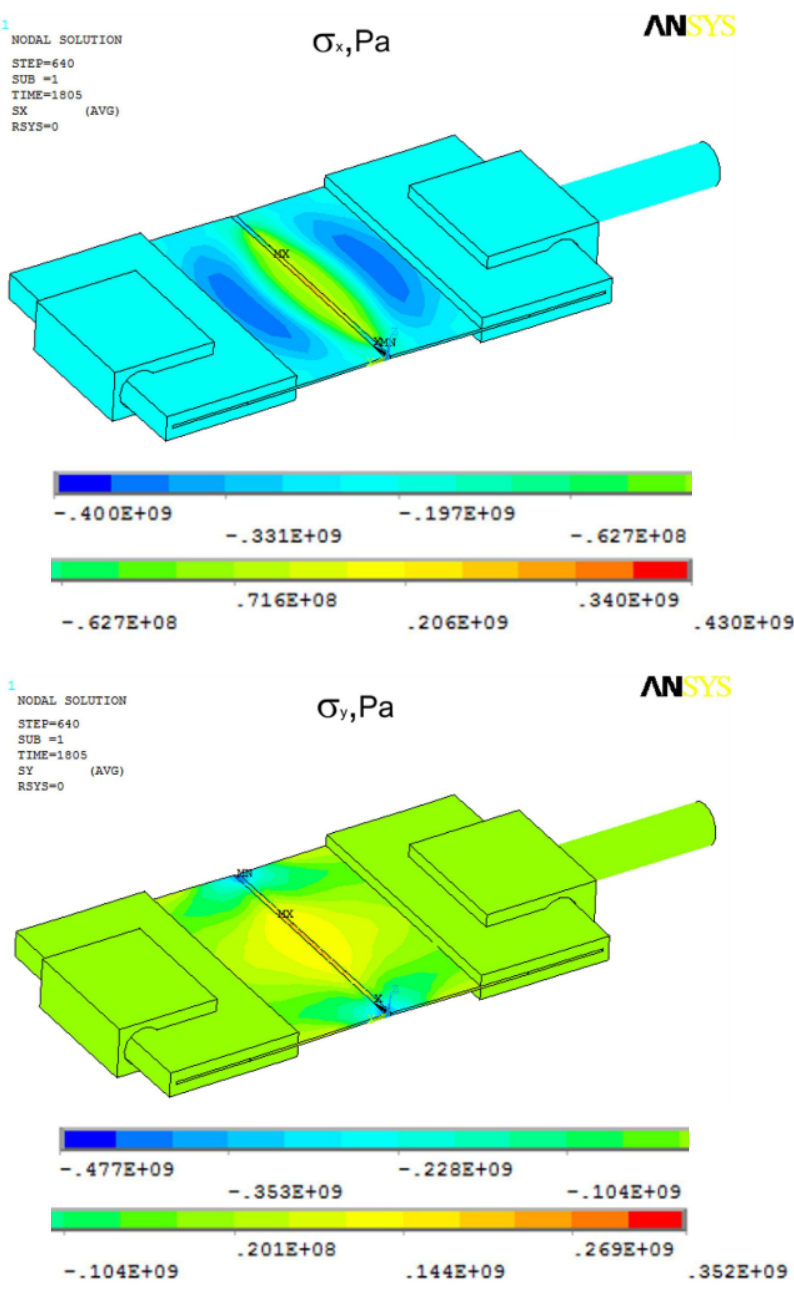

Fig. 14. Distribution of the normal residual stresses at time $1805 \mathrm{~s}$ for CC-GTAW ( $\sigma_{x}-$ longitudinal stress; $\sigma_{y}-$ transverse stress).

Since the internal forces in the PC-GTA weld were lower than those of the CC-GTA weld, it might be expected that the same tendency applies for the values of the corresponding residual stresses and their distribution in the PC-GTA weld.

In the present study the measurement of the temperature and internal forces arising during welding far from the weld seam was possible because of the use of the special experimental device. The accuracy of the computational models was assessed by the relation between the calculated and measured forces. On the basis of this the results gained from the numerical models could be verified. And so, the difficulties experienced in the real time measurement of stresses and strains were removed.

It is well known that thermomechanical material data are temperature dependent and play a key role for the accuracy of the computational model. Also it is recommended that the material data in the temperature range close to the melting point of the base metal are to be adopted with alternative methods $[8,15]$, characterized by a fair approach to accuracy. Further on, the data should be applied over several test solutions until a good correspondence is achieved between computational and available experimental values. At the end of this procedure the computational values obtained would be very close to the real material properties data and may be used in computational models with similar solution algorithms and process parameters. Consequently, the use of the experimental device might open new possibilities for computerized determination of the real thermomechanical data of the materials subjected to welding. This procedure is to be tested in a following study.

\section{Conclusions}

As a result from the experimental and numerical study of the forces and residual stresses in $316 \mathrm{~L}$ stainless steel welds produced under PC-GTAW and CC-GTAW the following conclusions can be drawn.

1. The heat input of the PC-GTAW used for the autogenous butt welds was found to be by $12 \%$ lower when compared with that of the CC-GTAW. As a consequence the peak temperature and the internal forces of the PC-GTA welds were lower than those of the CCGTA welds. The weld geometry and the absence of weld imperfections of both covered the highest quality requirements of ISO 5817, level B.

2. Weld thermal cycles at different points of the welds were obtained. For $t>400 \mathrm{~s}$ after the welding start there was a good agreement between the experimental and calculated temperature values. The discrepancies established at $t<400 \mathrm{~s}$ were attributed to the thermomechanical material data, which were considered unreliable within the temperature range from $900^{\circ} \mathrm{C}$ to the melting point of the base metal.

3. Internal forces represented by the bending moments, torque moment and the normal force were calculated far from the weld seam and measured by the special experimental device used in this study. Verification of the numerical model based on the correspondence between the calculated and measured forces was done. After an initial transient process, there was a good agreement between the experimental and numerical values. Therefore, the experimental device might open new possibilities for determining and testing thermomechanical material data.

4. Normal residual stresses were measured and modeled for the CC-GTAW in both the longitudinal and transverse direction. It was found out that the stresses were positive and the peak value of the longitudinal stress amounted to $80 \%$ of the base metal yield stress. The magnitude of the numerically obtained residual stress values was found to be $16 \%$ to $19 \%$ above the measured one. 


\section{References}

1. A. Guljaev, Physical Metallurgy (Mashinostroenie, Moskow, 1977)

2. H. Cary, Modern welding technology, 4 th ed., (Prentice Hall, Englewood Cliffs, NJ, 1998)

3. A. Zhelev, Materials Engineering. Manufacturing processes and processability, Sofia (2002)

4. D. Kotecki, F. Armao, Stainless steels properties how to weld them where to use them (The Lincoln Electric Company, 2003)

5. A. Lakshminarayanan, K. Shanmugam, V. Balasubramanian, Effect of autogenous arc welding processes on tensile and impact properties of ferritic stainless steel joints, Journal of Iron and Steel Research, 16(1), 62-68 (2009)

6. K. Tseng, C. Chou, The effect of pulsed GTA welding on the residual stress of a stainless steel weldment, Journal of Materials Processing Technology, 123, 346-353 (2002)

7. V. Vinokurov, Weld stresses and deformations (Machinostroenie, Moskow, 1968)

8. D. Radaj, Welding residual stresses and distortion. Calculation and measurement, (DVS Verlag, 2003)

9. T. Toyooka, T. Tsunerari, R. Ide, T. Tange, Fatugue test of residual stress induced specimens in carbon steel, Welding Journal, 64(1), 29-36 (1985)

10. ASTM Standard E837-13a, Determining residual stresses by the hole-drilling strain-gage method.

11. Y. Arai, M. Kikuchi, T. Watanabe, M. Nagaki, Residual stresses due to welding and its effect on the assessment of cracks near the weld interface, International Journal of Pressure Vessels and Piping, 63, 237-248 (1995)

12. P. Withers, H. Bhadeshia, Residual stress. Part 1 Measurement techniques, Materials Science and Technology, 17, 355-365 (2001)

13. T. Holden, J. Root, V. Fidleria, R. Holt, G. Roy, Application of neutron diffraction to engineering problems, Material Science Forum, 27-28, 359-370 (1988)

14. M. Park, H. Yang, D. Jang, J. Kim, T. Jin, Residual stress measurement on welded specimen by neutron diffraction, Journal of Materials Processing Technology, 155-156, 1171-1177 (2004)

15. J. Goldak, M. Akhalaghi, Computational welding mechanics, (Springer Verlag, 2005)

16. C. Schwenk, M. Rethmeier, Material properties for welding simulation - measurement, analysis, and exemplary data, Welding Journal, 90(6), 220-227 (2011)

17. M. Onsøien, M. M`hamdi, O. Akselsen, Residual stresses in weld thermal cycle simulated specimens of X70 pipeline steel, Welding Journal, 89(6), 127-132 (2010)

18. V. Tsonev, Determination of mechanical characteristics of a new alloy steel at high temperatures and static load, BulTrans-2010 Proceedings, 209-211 (2010)

19. P. Ghosh, K. Devakumaran, A. Pramanick, Effect of pulse current on shrinkage stress and distortion in multipass GMA welds of different groove size, Welding Journal, 89(3), 43-53 (2010)

20. V. Goyal, P. Ghosh, J. Sainic, Analytical studies on thermal behaviour and geometry of weld pool in pulsed current gas metal arc welding, Journal of Materials Processing Technology, 209, 1318-1336 (2009)

21. P. Ghosh, A. Ghosh, Control of residual stresses affecting fatigue life of pulsed current gas metal arc weld of high strength aluminum alloy, Metallurgical and Materials Transactions A, 35(8), 2439-2444 (2004)

22. S. Kulkarni, P. Ghosh, S. Ray, Improvement of weld characteristics by variation in welding processes and parameters in joining of thick wall 304LN stainless steel pipe, ISIJ International, 48(11), 1560-1569 (2008)

23. P. Ghosh, S. Gupta, H. Randhawa, Analytical studies on characteristics of vertical up bead on plate weld deposition using pulsed current GMAW, International Journal for the Joining of Materials, 12(3), 76-85 (2000)

24. L. Lazov, I. Muhtarov, V. Tsonev, Method for examination of forces in butt single pass arc welded joins, Journal of the Technical University Sofia, branch Plovdiv, 14, 179-184 (2009)

25. L. Lazov, I. Muhtarov, P. Petrov, Modeling of Temporary and Residual Stresses and Strains in Arc Welded Joints, Journal of the Technical University Sofia, branch Plovdiv, 14, 173-178 (2009)

26. T. Iamboliev, I. Muhtarov, T. Petrov, Investigation of the temperature field and forces under GMAW of double pass butt welds, Proceedings of the $2^{\text {nd }}$ SE IIW Congress, Sofia, 272-276 (2010)

27. L. Yajiang, W. Juan, C. Maoai, S. Xiaoqin, Finite element analysis of residual stress in the welded zone of high strength steel, Bulletin of Materials Science, 27, 127-132 (2004)

28. ISO 15614-1:2004, Specification and qualification of welding procedures for metallic materials. Welding procedure test. Part 1: Arc and gas welding of steels and arc welding of nickel and nickel alloys

29. ANSYS User's manual, (Swanson Analysis Systems, Inc., Houston, 1998)

30. Lucefin Group catalog data, www.lucefin.com

31. T. Iamboliev, Optimizing pulse GTA welding of austenitic stainless steel 1.4404, Proceedings of science conference, Ruse University, 51(2), 196-200 (2012) 